in vivo $34: 2687-2691(2020)$

doi:10.21873/invivo.12088

\title{
Metronomic Oral Vinorelbine: An Alternative Schedule in Elderly and Patients PS2 With Local/Advanced and Metastatic NSCLC Not Oncogene-addicted
}

\author{
DAVID ROSSI ${ }^{1}$, PAOLO LIPPE ${ }^{1}$, MARCO BRUNO LUIGI ROCCHI ${ }^{2}$, DONATELLA SARTI ${ }^{1}$, \\ VINCENZO CATALANO ${ }^{1}$, FRANCESCO GRAZIANO ${ }^{1}$, PAOLO GIORDANI $^{1}$, ANNAMARIA BALDELLI ${ }^{1}$, \\ STEFANO LUZI FEDELI ${ }^{1}$, LUCA IMPERATORI ${ }^{1}$, GIANLUCA LAICI ${ }^{1}$, CLAUDIA CAPPELLETTI $^{1}$, \\ TIZIANA TAMBURRANO ${ }^{1}$, RAFFAELLA BRACCI $^{1}$ and PAOLO ALESSANDRONI ${ }^{1}$ \\ ${ }^{1}$ Operative Oncology Unit, Azienda Ospedaliera Ospedali Riuniti Marche Nord, Pesaro, Italy; \\ ${ }^{2}$ Biomolecular Science Department, University of Urbino, Urbino, Italy
}

\begin{abstract}
Background: The MILES and ELVIS studies showed that vinorelbine is one of the best options for elderly patients with advanced non-small-cell-lung cancer (NSCLC). Oral vinorelbine at standard schedule $\left(60-80 \mathrm{mg} / \mathrm{m}^{2} /\right.$ weekly) has good activity in terms of response rates and progressionfree survival. In recent years, a metronomic schedule of oral vinorelbine (40-50 mg/m² three times a week, continuously) has been studied in phase II trials, especially in unfit and elderly patients. In the MOVE trial metronomic oral vinorelbine had a clinical benefit [partial response $(P R)+$ stable disease $(S D)>12$ weeks] in $58.1 \%$ of patients with mild toxicity. On this basis, in 2017 we started a phase II study with metronomic oral vinorelbine in elderly (over 70 years) or unfit [Eastern Cooperative Oncology Group performance score (ECOG-PS) of 2] patients with locally/advanced and metastatic NSCLC. Primary aims were clinical benefit ( $P R+S D \geq 6$ months $)$ and toxicity; secondary aims were progression-free survival and overall survival. Patients and Methods: A total of 25 patients entered the study: 11 with local/advanced and 14 with metastatic NSCLC (five squamous and 20 adenocarcinoma). None of the patients had epidermal growth factor receptor (EGFR) mutations, anaplastic lymphoma kinase (ALK) translocation, or programmed death ligand 1 (PDL1) expression; those with squamous carcinoma did not have PDL1 expression. The median age was 79 (range $=44-90)$ years. The PS was 0 in 12
\end{abstract}

This article is freely accessible online.

Correspondence to: David Rossi, MD, Operative Oncology Unit, Azienda Ospedaliera Ospedali Riuniti Marche Nord, via Lombroso, 61122 Pesaro, Italy. E-mail: david.rossi@ospedalimarchenord.it

Key Words: Oral, vinorelbine, metronomic, NSCLC. patients (48\%), 1 in four patients (16\%) and 2 in nine patients (36\%). Oral vinorelbine was administered at $40 \mathrm{mg}$ three times a week continuously. Results: Clinical benefit was achieved in eight patients (32\%). Objective responses were partial response in two patients (8\%), stable disease in seven (28\%), progressive disease in nine (36\%); seven patients were not evaluable for response (28\%). Median progression-free survival was 2 months; median overall survival was 4 months but four out of eight patients with clinical benefit were still alive at 18 months. Overall survival at 1 year was $32 \%$. Toxicity was mild: only one patient experienced grade 4 neutropenia, one grade 3 peripheral neuropathy, four grade 2 asthenia, one grade 2 mucositis, and one grade 2 diarrhoea. The dose needed to be reduced to $30 \mathrm{mg} / \mathrm{m}^{2} /$ three times a week in three patients. Conclusion: Our study confirmed the activity and safety of metronomic oral vinorelbine in patients with wild-type local/advanced and metastatic NSCLC unsuitable for treatment with standard i.v. chemotherapy, allowing patients a comfortable home-based therapy, thereby avoiding frequent hospital visits.

Lung cancer is the leading cancer killer in men and women in Europe with 388,000 estimated deaths in 2018 (1). In recent years, a number of new drugs have been approved for patients with 'oncogene-addicted' lung cancer: Osimertinib is now the gold standard agent for patients with epidermal growth factor receptor (EGFR) mutations, (2); pembrolizumab is the only check-point inhibitor for patients with programmed death ligand 1 (PDLl) expression $\geq 50 \%$ (squamous and non-squamous) (3); crizotinib is the only anaplastic lymphoma kinase $(A L K)$ inhibitor for patients with ROS proto-oncogene 1, receptor tyrosine kinase rearrangement (4); alectinib has demonstrated its efficacy as compared to crizotinb as first-line therapy in patients with $A L K$ translocations (5); and the combination of dabrafenib and trametinib is the best option for patients with B-Raf proto- 
oncogene, serine/threonine kinase (BRAF) V600E mutation (6). To date, in Italy, for fit patients [Eastern Cooperative Oncology Group performance score (ECOG-PS) 0-1] without PDL1 expression or acquired mutations, chemotherapy with a doublet of cisplatin/carboplatin (plus pemetrexed for adenocarcinoma or gemcitabine/vinorelbine for squamous carcinoma) is the mainstay of treatment. Very recently, pembrolizumab plus cisplatin/carboplatin and pemetrexed has been approved and reimbursable for patients with non-squamous lung cancer without PDL1 expression or with $\leq 50 \%$ expression (6). However, in clinical practice, the treatment of elderly or unfit patients with wild-type genotype remains a challenge. These are patients unsuitable for cisplatin or a chemotherapy combination, and a palliative monotherapy is generally the treatment of choice. The MILES and ELVIS studies showed that vinorelbine is one of the best options for elderly patients with advanced NSCLC $(8,9)$. Oral vinorelbine demonstrated good activity in terms of response rates and progression-free survival (10); moreover, the oral formulation is best suited for palliative treatment and allows home therapy. In order to minimize sideeffects (especially haematological toxicity), a metronomic schedule (40-50 mg three days a week, continuously) has been tested in phase II studies. Camerini et al. achieved a clinical benefit $[\mathrm{CB}$; partial response $(\mathrm{PR})+$ stable disease $(\mathrm{SD}) \geq 6$ weeks] of $58.1 \%$ in elderly patients with mild toxicity (11). Similar results were published by Mencoboni et al. with $50 \%$ clinical benefit and only $10.5 \%$ grade 3 toxicity (12). On this basis, in 2017 we started a phase II study with metronomic oral vinorelbine in elderly (over 70 years) or unfit (ECOG PS 2) patients with local/advanced and metastatic NSCLC. Primary aims were $\mathrm{CB} \geq 6$ months and toxicity; secondary aims were progression-free survival and overall survival.

\section{Patients and Methods}

Eligibility criteria. Patients with cytologically or histologically and measurable locally advanced, according to the seventh edition of the TNM classification (13), and metastatic (stage IV) NSCLC entered the study. All patients had to be without oncogene addiction: EGFR mutations, ALK translocations, ROS1 rearrangement and PDL1 expression was obtained before starting treatment for patients with adenocarcinoma histology; and PDL1 expression for patients with squamous histology. Other selection criteria included: Age $\geq 70$ years with ECOG PS 0-2 or $<70$ years with ECOG PS 2, adequate liver, renal and bone marrow function and life expectancy of at least 3 months. Previous radiotherapy was accepted when measurable lesions were present in a non-irradiated area. Patients with symptomatic brain metastases were excluded from the study. Staging procedures included physical examination, chest, abdomen and brain computed tomographic scan and positron-emission tomography total-body scan.

Study design and statistical methods. Primary objectives of the study were $\mathrm{CB}$ (defined as complete response or PR plus SD $\geq 6$ months) and toxicity. Secondary aims were progression-free and overall survival. Response to therapy was assessed according to the RECIST criteria 1.1 (14) after the first 12 administrations. Only patients with objective response or SD carried on treatment until disease progression. Toxicity was evaluated at all administrations according to National Institutes of Health and National Cancer Institute Common Terminology Criteria for Adverse Events criteria 5.0 (15). Progression-free-survival was calculated from day 1 of the first cycle to the first documentation of progression; overall survival was calculated from day 1 of the first cycle to the date of death or last follow-up. Median survival was calculated according to the KaplanMeier method. According to the intention-to-treat-analysis, all patients were evaluated for each aim of the study. The sample size was calculated according to the number of objective responses for vinorelbine monotherapy [i.v. vinorelbine $20 \%$ and oral vinorelbine $12 \%$ in studies by Gridelli (9) and Jassem et al. (10), respectively]. On this basis, we assumed that a $\mathrm{CB}$ of $30 \%$ was a good measure of activity for metronomic oral vinorelbine. According to the method of Miettinen (16), in order to minimize the size of the $95 \%$ confidence interval, 25 patients were required. As can be seen from Table I, with 25 patients (corresponding to seven or eight cases of $\mathrm{CB}$ ), the expected $95 \%$ confidence interval was lower than $4 \%( \pm 2 \%)$. Nevertheless, according to the same method, with two events of grade 3 or 4 toxicity $(8 \%)$, the $95 \%$ confidence interval was between $7.6 \%$ and $11.5 \%(\sim 4 \%)$, which we assumed to be an acceptable value.

Oral vinorelbine was administered at the dose of $40 \mathrm{mg}$ (two capsules of $20 \mathrm{mg}$ ) three days a week after lunch (Monday, Wednesday and Friday) continuously, until disease progression, patient refusal or development of unacceptable toxicity. Each vinorelbine administration was preceded by oral ondansetron (1 hour before). Patients were followed-up every cycle (we considered three weeks a cycle), with a complete blood cell count and serum chemistry performed. Granulocyte colony-stimulating factors were permitted only for patients with febrile neutropenia or with grade 4 neutropenia (even without fever). On grade 3 or 4 toxicity or grade 2 toxicity with severe deterioration of daily activities, the dose was reduced to $30 \mathrm{mg}$; if another grade 3 toxicity occurred, the treatment was definitively stopped. The study was approved by the Regional Ethical Committee (NCT04208854). Written-informed consent was required for all patients.

\section{Results}

From March to 2017 to March 2019, 25 patients entered the study. Eleven patients had local/advanced disease and 14 had metastatic NSCLC (five squamous and 20 adenocarcinoma). There were 12 females and 13 males with a median age of 79 years (range $=44-90$ years). ECOG PS was 0 in 12 patients, 1 in eight patients and 2 in five patients.

Objective responses were as follow: PR in two patients $(8 \%)$, SD in seven patients $(28 \%)$, and progressive disease in nine patients $(36 \%)$. Median progression-free survival was 2 months; median overall survival was 4 months and four out of eight patients with $\mathrm{CB}$ were still alive at 18 months. Overall survival at 1 year was $32 \%$. We observed a CB in eight patients $(32 \%)$.

Two patients stopped chemotherapy due to toxicity: One patient experienced grade 4 neutropenia during the first cycle and was treated with granulocyte colony stimulating factors; one patient experienced grade 3 peripheral neuropathy, 
Table I. Statistical analysis of event risk according to the method of Miettinen (13). For seven or eight cases of clinical benefit, corresponding to 25 patients, the expected $95 \%$ confidence interval was lower than $4 \%( \pm 2 \%)$ (shown in bold).

\begin{tabular}{lcc}
\hline $\begin{array}{l}\text { Number of } \\
\text { patients }\end{array}$ & $\begin{array}{c}\text { Percentage } \\
\text { of patients }\end{array}$ & $95 \%$ CI \\
\hline 1 & 0.04 & $0.038462-0.076834$ \\
2 & 0.08 & $0.076923-0.115377$ \\
3 & 0.12 & $0.115385-0.153846$ \\
4 & 0.16 & $0.153846-0.192308$ \\
5 & 0.20 & $0.192308-0.230769$ \\
6 & 0.24 & $0.230769-0.269231$ \\
7 & $\mathbf{0 . 2 8}$ & $\mathbf{0 . 2 6 9 2 3 1 - 0 . 3 0 7 6 9 2}$ \\
$\mathbf{8}$ & $\mathbf{0 . 3 2}$ & $\mathbf{0 . 3 0 7 6 9 2 - 0 . 3 4 6 1 5 4}$ \\
9 & 0.36 & $0.346154-0.384615$ \\
10 & 0.46 & $0.384615-0.423077$ \\
11 & 0.44 & $0.423077-0.461538$ \\
12 & 0.48 & $0.461538-0.500000$ \\
13 & 0.52 & $0.500000-0.538462$ \\
14 & 0.56 & $0.538462-0.576923$ \\
15 & 0.60 & $0.576923-0.615385$ \\
16 & 0.64 & $0.615385-0.653846$ \\
17 & 0.68 & $0.653846-0.692308$ \\
18 & 0.72 & $0.692308-0.730769$ \\
19 & 0.76 & $0.730769-0.769231$ \\
20 & 0.80 & $0.769231-0.807692$ \\
21 & 0.84 & $0.807692-0.846154$ \\
22 & 0.88 & $0.846154-0.884615$ \\
23 & 0.92 & $0.884623-0.923077$ \\
24 & 0.96 & $0.923166-0.961538$ \\
\hline & &
\end{tabular}

CI: Confidence interval.

confirmed by electromyography, after 12 months of treatment. Other toxicities are given in Table III. In three, patients the dose was reduced to $30 \mathrm{mg}$ (one capsule) three times a week and continued at the same dose. Seven patients (28\%) were not evaluable for objective response or CB (Table II). All these patients received only one cycle (four patients showed fast worsening of clinical condition, two were 90 years old and treatment was stopped; one patient experienced grade 4 neutropenia after the first month of treatment; one patient died after the first 4 weeks of treatment; one patient refused to continue administration after grade 3 asthenia. Eight patients (32\%) underwent a second-line therapy (six with gemcitabine and two with immunotherapy).

\section{Discussion}

Treatment of elderly (age $\geq 70$ years) or unfit patients (ECOG PS 2) with local/advanced or metastatic NSCLC is still a challenge, even in 2020. This is harder for patients without mutations and the "old" chemotherapy remains the treatment of choice. Monotherapy with gemcitabine or vinorelbine is the best option for these patients even though
Table II. Results of therapy and grade 3-4 toxicity.

\begin{tabular}{llc}
\hline & & Number of patients (\%) \\
\hline \multirow{2}{*}{ Response } & Clinical benefit & $8(32 \%)$ \\
& Partial response & $2(8 \%)$ \\
& Stable disease & $7(28 \%)$ \\
& Progressive disease & $9(36 \%)$ \\
& Not evaluable for response & $7(28 \%)$ \\
\multirow{2}{*}{ Toxicity } & Complete response & 0 \\
& Grade 4 neutropenia & $1(4 \%)$ \\
& Grade 3 neurological toxicity & $1(4 \%)$ \\
\hline
\end{tabular}

Table III. Other toxicities experienced by patients under the study therapy.

\begin{tabular}{lc}
\hline Toxicity & Number of patients (\%) \\
\hline Grade 2 asthenia & $4(16 \%)$ \\
Grade 2 mucositis & $1(1 \%)$ \\
Grade 2 diarrhoea & $1(1 \%)$ \\
Grade 2 anorexia & $4(16 \%)$ \\
Grade 1 asthenia & $1(1 \%)$ \\
Grade 1 diarrhoea & $1(1 \%)$ \\
\hline
\end{tabular}

Quoix et al. reported a survival advantage of carboplatin/paclitaxel combination versus monotherapy (17). In the ELVIS trial, an absolute survival advantage of intravenous vinorelbine versus best supportive care alone was demonstrated, with an overall survival of 28 weeks as compared to 21 weeks (9). In the MILES study, intravenous vinorelbine or gemcitabine resulted in an overall survival ranging from 28 to 36 weeks, with a time-to-progression of 17-18 weeks (8). Jassem et al. published data for use of oral versus intravenous vinorelbine: the activity of the two drugs formulation was comparable in terms of objective response rates, progression free-survival and toxicity (nausea, vomiting, diarrhoea, anorexia were more common in the oral arm (10).

In the past 5 years, a metronomic formulation of vinorelbine has been tested in a number of phase II NSCLC studies, especially in frail patients such as the elderly and unfit. In 2015, Camerini et al. reported one of the first experiences with this new oral formulation: 43 chemo-naive elderly patients were treated with metronomic vinorelbine at the dose of $50 \mathrm{mg}$ three times a week, continuously. This therapy achieved a clinical benefit $(\mathrm{PR}+\mathrm{SD} \geq 6$ weeks) of $58.1 \%$ (with a response rate of $18 \%$ ), median time-toprogression of 5 months and overall survival of 9 months; the treatment was well tolerated with rare serious toxicity 
(11). Mencoboni et al., in 2107, published a phase II study in 66 elderly patients reporting a CB in $50 \%$ of patients, with mild toxicity (12). Other phase II trials confirmed good activity and safety of metronomic formulation of vinorelbine in elderly and unfit patients $(18,19)$.

To the best of our knowledge, the present study is the only one that used a fixed dose of $40 \mathrm{mg}$, other trials used a fixed dose of $50 \mathrm{mg}, 30 \mathrm{mg}$ or mixed doses of 20/30/50 mg, $30 / 40 / 50, \mathrm{mg}$, or 30/40 mg (20). Our main objective was CB, indicated as objective response plus $\mathrm{SD} \geq 6$ months, which we consider a more reliable value of activity as compared with objective response plus $\mathrm{SD} \geq 6$ weeks or objective response plus SD chosen by Camerini et al. (11) and Mencoboni et al. (12), respectively.

In our study, the primary aim was reached, with $32 \%$ of patients with $\mathrm{CB}$, which was remarkable considering the median age of patients (79 years) and the percentage of those with ECOG 2 (36\%). Unfortunately, progression-free (median of 2 months) and overall (median of 4 months) survival were very poor as compared to previous studies $(11,12)$. Even though in phase II study, progression-free and overall survival are always secondary aims, we analysed these poor data and believe that they might be related to the early discontinuation of seven patients (28\%). However, overall survival at 1 year was $32 \%$, which was somewhat comparable to other studies (11). Moreover, four out of eight patients with $\mathrm{CB}$ were still alive at 18 months.

Toxicity was encouraging: Only two patients experienced grade 3 or 4 toxicity ( $8 \%$ ), confirming results of Mencoboni et al. (12) with better safety profile of metronomic vinorelbine as compared to the conventional regimen. In 2019, a metaanalysis of metronomic oral vinorelbine was published (20) and included nine studies, in first- and second-line therapy. Results were a median progression-free-survival of 4.2 months, median overall survival of 8.7 months, and grade 3-4 toxicity of $15.8 \%$. The authors concluded that "metronomic oral vinorelbine is an active and well-tolerated single-drug chemotherapy regimen in metastatic NSCLC and is a manageable therapy in frail patients". On the basis of our study and latest literature, we agree with the aforementioned sentence and consider metronomic vinorelbine to be a valuable option for patients with local/advanced and metastatic NSCLC without oncogenic drivers.

\section{Conflicts of Interest}

The Authors declare no conflicts of interest in regard to this study.

\section{Authors' Contributions}

All Authors equally contributed to planning and conduction of the study. All Authors approved the final version of the article.

\section{References}

1 Ferlay J, Colombet M, Soerjomataram I, Dyba T, Randi G, Bettio M, Gavin A, Visser O and Bray F: Cancer incidence and mortality patterns in Europe: Estimates for 40 countries and 25 major cancers in 2018. Eur J Cancer 103: 356-387, 2018. PMID: 30100160. DOI: 10.1016/j.ejca.2018.07.005

2 Soria JC, Ohe Y, Vansteenkiste J, Reungwetwattana T, Chewaskulyong B, Lee KH, Dechaphunkul A, Imamura F, Nogami N, Kurata T, Okamoto I, Zhou C, Cho BC, Cheng Y, Cho EK, Voon PJ, Planchard D, Su WC, Gray JE, Lee SM, Hodge R, Marotti M, Rukazenkov Y and Ramalingam SS; FLAURA Investigators: Osimertinib in untreated EGFR-mutated advanced non-small-cell lung cancer. N Engl J Med 378(2): 113125, 2018. PMID: 29151359. DOI: 10.1056/NEJMoa1713137

3 Reck M, Rodrìguez-Abreu D, Robinson A, GHui R, Csőszi T, Fülöp A, Gottfried M, Peled N, Tafreshi A, Cuffe S, O'Brien M, Rao S, Hotta K, Leiby MA, Lubiniecki GM, Shentu Y, Rangwala R and Brahmer JR; KEYNOTE-024 Investigators: Pembrolizumab versus chemotherapy for PDL-1-positive nonsmall-cell lung cancer. N Engl J Med 375(19): 1823-1833, 2016. PMID: 27718847. DOI: 10.1056/NEJMoa1606774

4 Shaw AT, I S.H. Ou, Bang YJ, Camidge DR, Solomon BJ, Salgia R, Riely GJ, Varella-Garcia M, Shapiro GI, Costa DB, Doebele RC, Le LP, Zheng Z, Tan W, Stephenson P, Shreeve SM, Tye LM, Christensen JG, Wilner KD, Clark JW and Iafrate AJ: Crizotinib in ROS-1-rearranged non-small-cell lung cancer. N Engl J Med 371(21): 1963-1971, 2014. PMID: 25264305. DOI: 10.1056/NEJMoa1406766

5 Peters S, Ross Camidge D, Shaw AT, Gadgeel S, Ahn JS, Kim DW, Ou SI, Pérol M, Dziadziuszko R, Rosell R, Zeaiter A, Mitry E, Golding S, Balas B, Noe J, Morcos PN and Mok T; ALEX Trial Investigators: Alectinib versus crizotinib in untreated $A L K$ positive non-small-cell lung cancer. N Engl J Med 377(9): 829838, 2017. PMID: 28586279. DOI: 10.1056/NEJMoa1704795

6 Planchard D, Smit EF, Groen HJM, Mazieres J, Besse B, Helland Å, Giannone V, D'Amelio AM Jr, Zhang P, Mookerjee $B$ and Johnson BE: Dabrafenib plus trametinib in patients with previously untreated $B R A F(\mathrm{~V} 600 \mathrm{E})$-mutant metastatic nonsmall-cell lung cancer: an open-label, phase 2 trial. Lancet Oncol 18(10): 1307-1316, 2017. PMID: 28919011. DOI: 10.1016/ S1470-2045(17)30679-4

7 Gandhi L, Rodrìguez-Abreu D, Gadgeel S, Esteban E, Felip E, De Angelis F, Domine M, Clingan P, Hochmair MJ, Powell SF, Cheng SY, Bischoff HG, Peled N, Grossi F, Jennens RR, Reck M, Hui R, Garon EB, Boyer M, Rubio-Viqueira B, Novello S, Kurata T, Gray JE, Vida J, Wei Z, Yang J, Raftopoulos H, Pietanza MC and Garassino MC; KEYNOTE-189 Investigators: Pembrolizumab plus chemotherapy in metastatic non-small-cell lung cancer. N Engl J Med 378(22): 2078-2092, 2018. PMID: 29658856. DOI: $10.1056 /$ NEJMoa 1801005

8 Gridelli C, Perrone F, Gallo C, Cigolari S, Rossi A, Piantedosi F, Barbera S, Ferraù F, Piazza E, Rosetti F, Clerici M, Bertetto O, Robbiati SF, Frontini L, Sacco C, Castiglione F, Favaretto A, Novello S, Migliorino MR, Gasparini G, Galetta D, Iaffaioli RV and Gebbia V; MILES Investigators: Chemotherapy for elderly patients with advanced non-small-cell lung cancer: The Multicenter Italian Lung Cancer in the Elderly Study (MILES) phase III randomized trial. J Natl Cancer Inst 95(5): 362-372, 2003. PMID: 12618501. DOI: 10.1093/jnci/95.5.362 
9 Gridelli C: The ELVIS Trial: A phase III study of single-agent vinorelbine as first-line treatment in elderly patients with advanced non-small cell lung cancer. Oncologist 6(Suppl 1): 4-7, 2001. PMID: 11181997. DOI: 10.1634/theoncologist.6-suppl_1-4

10 Jassem J, Ramlau R, Karnicka-Mlodkowska H, Krawczyk K, Krzakowski M, Zatloukal P, Lemarié E, Hartmann W, Novakova L, O'Brien $\mathrm{M}$ and Depierr A: A multicenter randomized phase II study of oral $v s$. intravenous vinorelbine in advanced non-smallcell lung cancer patients. Ann Oncol 12(10): 1375-1381, 2001. PMID: 11762807. DOI: 10.1023/a:1012539225493

11 Camerini A, Puccetti C, Donati S, Valsuani C, Petrella MC, Tartarelli G, Puccinelli P and Amoroso D: Metronomic oral vinorelbine as first-line treatment in elderly patients with advanced non-small cell lung cancer: Results of a phase II trial (MOVE trial). BMC Cancer 6(15): 359, 2015. PMID: 25943747. DOI:10.1186/s12885-015-1354-2

12 Mencoboni M, Filiberti RA, Taveggia P, Del Corso L, Del Conte A, Covesnon MG, Puccetti C, Donati S, Auriati L, Amoroso D and Camerini A: Safety of first-line chemotherapy with metronomic single-agent oral vinorelbine in elderly patients with NSCLC. Anticancer Res 37(6): 3189-3194, 2017. PMID: 28551663. DOI: 10.21873 /anticanres.11679

13 Goldstraw P: New TNM classification: achievements and hurdles. Transl Lung Cancer Res 2(4): 264-272, 2013. PMID: 25806242. DOI: 10.3978/j.issn.2218-6751.2013.07.02

14 Lowrence H, Schwartz LH, Litiere S, de Vries E, Ford R, Gwyther S, Sumithra M, Shankar L, Bogaerts J, Chen A, Dancey J, Hayes W, Hodi FS, Hoekstra OS, Huang EP, Lin N, Liu Y, Therasse P, Wolchok JD and Seymour L: RECIST 1.1-Update and clarification from the RECIST Committee. Eur J Cancer 62: 132137, 2016. PMID: 27189322. DOI: 10.1016/j.ejca.2016.03.081

15 National Institutes of Health and National Cancer Institute. Common Terminology Criteria for Adverse Events (CTCAE) Version 5.0. U.S. Department of Health and Human Sciences; National Institutes of Health and National Cancer Institute; 2017. Available at: https://ctep.cancer.gov/protocolDevelopment/ electronic_applications/docs/CTCAE_v5_Quick_Reference_5x7. pdf [Last accessed on May 5th, 2020]
16 Miettinen OS: Estimation of relative risk from individually matched series. Biometrics 26: 75-86, 1970. PMID: 5461791.

17 Quoix E, Zalcman G, Oster JP, Westeel V, Pichon E, Lavolé A, Dauba J, Debieuvre D, Souquet PJ, Bigay-Game L, Dansin E, Poudenx M, Molinier O, Vaylet F, Moro-Sibilot D, Herman D, Bennouna J, Tredaniel J, Ducoloné A, Lebitasy MP, Baudrin L, Laporte $\mathrm{S}$ and Milleron B; Intergroupe Francophone de Cancérologie Thoracique: Carboplatin and weekly paclitaxel doublet chemotherapy compared with monotherapy in elderly patients with advanced non-small-cell lung cancer: IFCT-0501 randomised, phase 3 trial. Lancet 378(9796): 1079-1088, 2011. PMID: 21831418. DOI: 10.1016/S0140-6736(11)60780-0

18 Bilir C, Durak S, Kizilkaya B, Hacıbekiroglu I, Nayır E and Engin $\mathrm{H}$ : Efficacy of metronomic vinorelbine in elderly patients with advanced non-small-cell lung cancer and poor performance status. Curr Oncol 24(3): 199-204, 207. PMID: 28680287. DOI: $10.3747 / \operatorname{co} .24 .3486$

19 Banna GL, Camerini A, Bronte G, Anile G, Addeo A, Rundo F, Zanghì G, Lal R and Libra M: Oral metronomic vinorelbine in advanced non-small cell lung cancer patients unfit for chemotherapy. Anticancer Res 38(6): 3689-3697, 2018. PMID: 29848729. DOI: 10.21873 /anticanres.12647

20 Pujol JL, Coffy A, Camerini A, Kotsakis A, Mencoboni M, Gusella M, Pasini F, Pezzuto A, Banna GL, Bilir C, Samantas E, Barlesi F, Roch B, Guillou A and Daurès JP: An individual patient-data metanalysis of metronomic oral vinorelbine in metastatic non-small cell lung cancer. PLoS One 14(8): e0220988, 2019. PMID: 31430345. DOI: 10.1371/journal.pone.0220988.

Received April 9, 2020

Revised May 1, 2020

Accepted May 6, 2020 